\title{
DiverseK - Integrating diverse knowledge systems for environmental policy
}

\author{
Daniele Colombaroli', M. Coughlan², Q. Cui ${ }^{3}$, C. Kulkarni ${ }^{4}$, J. Mistry ${ }^{1}$ and E. Razanatsoa ${ }^{5}$
}

There is a growing need for more sustainable approaches to tackle future environmental and human livelihood challenges, including biodiversity losses following land-use intensification, and climate impacts under future warmer conditions (Fischer et al. 2018). Conservation plans often lack the full knowledge base to address such challenges (Fig. 1), resulting in conflicts between restoration targets and people's needs. For example, management policies such as fire suppression often contrast with traditional fire-use practices to sustain local livelihoods, or they undermine the key role of disturbance regimes for long-term ecological succession (Coughlan 2013; Kulkarni et al. 2021).

The goal of PAGES' new DiverseK working group is to merge diverse types of local and regional knowledge from science and stakeholders, and to build a more integrative, cross-disciplinary evidence base for better decision-making on environmental and social justice issues. The Intergovernmental Science-Policy Platform on Biodiversity and Ecosystem Services (IPBES) only recently adopted a specific framework for Indigenous knowledge (IPBES-5/1), but the role of past legacies and long-term ecological processes are still overlooked in ecosystem management, despite their relevance (e.g. Gillson and Marchant 2014). Synergies between long-term ecology and local/Indigenous knowledge can better support conservation policies to meet landscape conservation targets, for example, by addressing the socialecological consequences of traditional land management, or identifying the natural and anthropogenic (biocultural heritage) components that maximize biodiversity and resilience in ecosystems (Colombaroli et al. 2019). Such synergies can also help support local communities and other stakeholders as they face the most pressing environmental issues, in ways that are more socially just (Mistry and Berardi 2016).

\section{Scientific objectives}

The objectives of DiverseK include methodological advancements, resolution of regional stakeholder-led challenges, and global-scale analyses. We will engage stakeholders in selected areas to foster dialog locally and use our integrated framework to discuss best practices for integration of local knowledge with other disciplines, including fire ecology, paleoecology, and dendroecology. This will provide the ground for a clearer methodological basis for diverse knowledge inclusion, which takes into account ethics and impacts of engagement with local people. Finally, we will focus on areas where conservation targets contrast with the traditional use by local communities and/or the paleoevidence (in terms of baselines, species turnover, community responses, etc.) and identify best management approaches that can be effective in local planning, drawing upon the new integrative knowledge in co-production with stakeholders.

\section{Opportunities for using diverse knowledge systems}

The mutual exchange between the scientific and stakeholder communities can provide new opportunities for conservation-based research. For paleoecologists, knowledge of contemporary local practices can aid the interpretation of paleorecords. For local

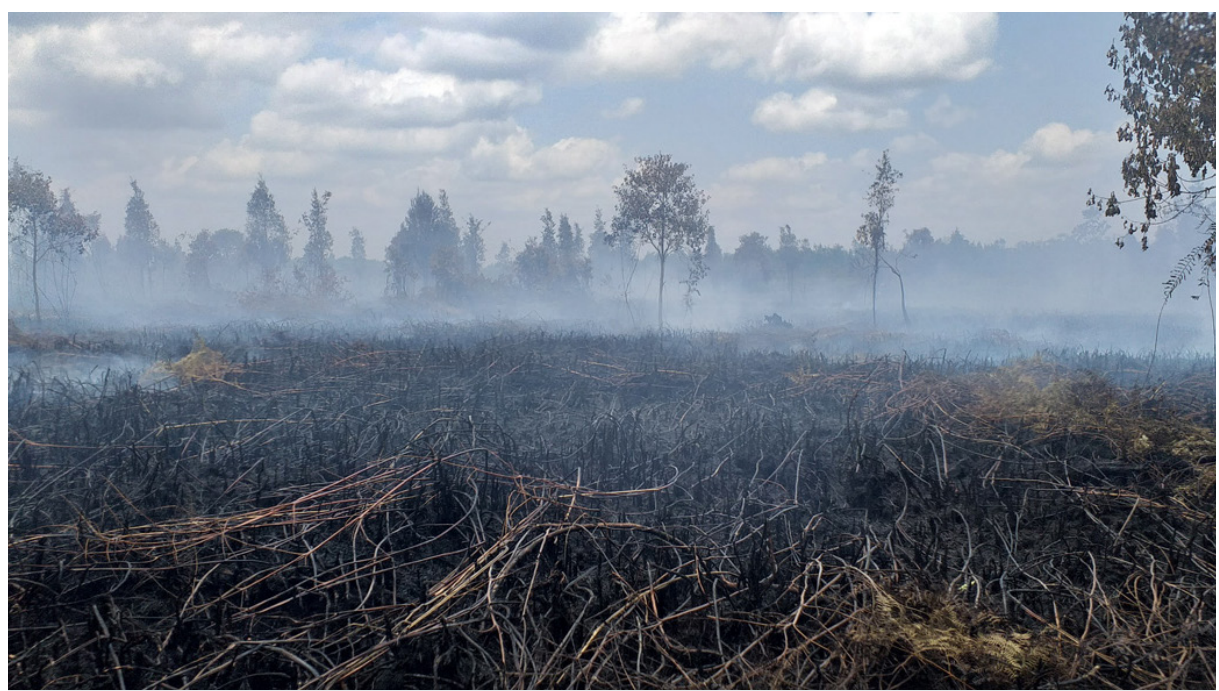

people, in the context of ongoing loss of traditional knowledge, paleoevidence can support local social and environmental-justice struggles. Together, the combination of paleoecology-informed, community-owned and stakeholder-driven knowledge developed from previous collaborations within the former Global Paleofire Working Group 2 (Vannière et al. this issue) can foster dialog between the different disciplines, promoting the inclusion of ecological and socio-cultural disciplines (traditionally separated in academia) and Indigenous knowledge, which represents a key challenge for the sciencepolicy interface (Colombaroli et al. 2019).

\section{Upcoming activities}

In the coming year, we plan a series of webinars to involve local communities, academics, and other stakeholders such as protected-area managers, in a process of intercultural exchange to inform environmental management. We welcome participants working at the interface between paleoecology and local knowledge to discuss existing approaches and develop guidelines for best practices.

Visit our website at pastglobalchanges. org/diversek and register for our mailing list to keep up to date with our activities. The working group is also supported by the Leverhulme Wildfires Centre (https:// centreforwildfires.org/) and the International Paleofire Network (https://ipn.paleofire.org)

\section{AFFILIATIONS}

'Department of Geography, Royal Holloway University of London, UK

${ }^{2}$ Institute for a Sustainable Environment, University of Oregon, Eugene, USA

${ }^{3}$ Key Laboratory of Land Surface Pattern and

Simulation, Institute of Geographical Sciences and Natural Resources Research, Chinese Academy of Sciences, Beijing, China

${ }^{4}$ Independent researcher, ckulkarni@gradcenter.cuny. edu

5Plant Conservation Unit, Department of Biological Sciences, University of Cape Town, South Africa

\section{CONTACT}

Daniele Colombaroli: Daniele.colombaroli@rhul.ac.uk

\section{REFERENCES}

Colombaroli D et al. (2019) Policy Brief. Royal Holloway

$$
\text { University of London, } 8 \mathrm{pp}
$$

Coughlan MR (2013) J Ethnobiol 33: 86-104

Fischer H et al. (2018) Nat Geosci 11: 474-485

Gillson L, Marchant R (2014) Trends Ecol Evol 29: 317-25

Kulkarni C et al. (2021) J Environ Manag 283: 111957

Mistry J, Berardi A (2016) Science 352: 1274-1275

Figure 1: Under warmer conditions and rapid land-use changes predicted for the future, tropical peatlands will require new conservation measures to mitigate the impacts of catastrophic fires (Image credit: Ibnu Fikri). 